\title{
Paired-Pulse Plasticity in the Strength and Latency of Light-Evoked Lateral Inhibition to Retinal Bipolar Cell Terminals
}

\author{
Evan Vickers, ${ }^{1}$ Mean-Hwan Kim, ${ }^{1}$ Jozsef Vigh, ${ }^{2}$ and Henrique von Gersdorff ${ }^{1}$ \\ ${ }^{1}$ The Vollum Institute, Oregon Health and Science University, Portland, Oregon 97239, and 2Department of Biomedical Sciences, Colorado State University, \\ Ft. Collins, Colorado 80523
}

\begin{abstract}
Synapses in the inner plexiform layer of the retina undergo short-term plasticity that may mediate different forms of adaptation to regularities in light stimuli. Using patch-clamp recordings from axotomized goldfish Mb bipolar cell (BC) terminals with paired-pulse light stimulation, we isolated and quantified the short-term plasticity of GABAergic lateral IPSCs (L-IPSCs). Bright light stimulation evoked ON and OFF L-IPSCs in axotomized BCs, which had distinct onset latencies $(\sim 50-80$ and $\sim 70-150$ ms, respectively $)$ that depended on background light adaptation. We observed plasticity in both the synaptic strength and latency of the L-IPSCs. With paired light stimulation, latencies of ON L-IPSCs increased at paired-pulse intervals (PPIs) of 50 and 300 ms, whereas OFF L-IPSC latencies decreased at the $300 \mathrm{~ms}$ PPI. ON L-IPSCs showed paired-pulse depression at intervals $<1 \mathrm{~s}$, whereas OFF L-IPSCs showed depression at intervals $\leq 1 \mathrm{~s}$ and amplitude facilitation at longer intervals $(1-2 \mathrm{~s})$. This biphasic form of L-IPSC plasticity may underlie adaptation and sensitization to surround temporal contrast over multiple timescales. Block of retinal signaling at GABA $\mathrm{A}_{\mathrm{R}}$ and AMPARs differentially affected ON and OFF L-IPSCs, confirming that these two types of feedback inhibition are mediated by distinct and convergent retinal pathways with different mechanisms of plasticity. We propose that these plastic changes in the strength and timing of L-IPSCs help to dynamically shape the time course of glutamate release from ON-type BC terminals. Short-term plasticity of L-IPSCs may thus influence the strength, timing, and spatial extent of amacrine and ganglion cell inhibitory surrounds.
\end{abstract}

\section{Introduction}

Inhibitory networks in the inner plexiform layer (IPL) of the retina, consisting of amacrine cell (AC) inputs to bipolar cell (BC) presynaptic terminals, serial synapses between AC dendrites, and direct inputs to ganglion cell (GC) dendrites, perform computations that shape GC output to the brain. For example, these inputs mediate spatial integration and refine GC centersurround receptive fields (Cook and McReynolds, 1998; Jacobs and Werblin, 1998; Ichinose and Lukasiewicz, 2005) and GC orientation selectivity (Venkataramani and Taylor, 2010). The goldfish Mb-type BC, a counterpart of the mammalian rod BC (RBC) (Euler and Masland, 2000; Joselevitch and Kamermans, 2009; Snellman et al., 2009), depolarizes in response to light stimulation (Wong et al., 2005) and has a large $(\sim 10 \mu \mathrm{m})$ synaptic terminal that stratifies in sublamina $b$ (ON layer) of the IPL (Witkovsky and Dowling, 1969). It is thus possible to patch clamp a single Mb BC terminal in retinal slices (Palmer et al.,

\footnotetext{
Received Feb. 5, 2012; revised June 9, 2012; accepted June 15, 2012.

Author contributions: E.V., M.-H.K., J.V., and H.v.G. designed research; E.V. and M.-H.K. performed research; E.V., M.-H.K., and H.v.G. analyzed data; E.V., M.-H.K., J.V., and H.v.G. wrote the paper.

This research was funded by National Institutes of Health/National Eye Institute Grants EY014043 (H.v.G.) and EY EY019051 (J.V.) and was partially supported by Korea Research Foundation Grant KRF-2008-357-E00032 (M.H.K.). We thank Drs. llya Buldyrev and W. Rowland Taylor for helpful discussions and comments on this manuscript.

Correspondence should be addressed to Henrique von Gersdorff, The Vollum Institute, Oregon Health and Science University, 3181 SW Sam Jackson Park Road, Portland, 0R 97239. E-mail: vongersd@ohsu.edu.

DOI:10.1523/JNEUROSCI.0547-12.2012

Copyright $\odot 2012$ the authors $\quad 0270-6474 / 12 / 3211688-12 \$ 15.00 / 0$
}

2003), which makes it an excellent model for the study of inhibitory processing in the IPL.

Each Mb terminal makes $\sim 50$ synapses with GC dendrites and $\sim 300$ synapses with AC boutons, of which $\sim 50 \%$ are reciprocal and $\sim 50 \%$ are lateral (Marc and Liu, 2000). Reciprocal synapses use AMPA and NMDA receptors on the $A C$ and $G A B A_{A} R$ and $\mathrm{GABA}_{\mathrm{C}} \mathrm{R}$ synapses on the $\mathrm{Mb}$ (Vigh and von Gersdorff, 2005), whereas lateral synapses exhibit unidirectional release of GABA onto the $\mathrm{Mb}$ (Marc and Liu, 2000). Several studies provide evidence that lateral and reciprocal synapses are spatially and functionally distinct (Marc and Liu, 2000; Zhang and Wu, 2009; Vigh et al., 2011). Immunohistochemical (Koulen et al., 1998) and electrophysiological (Palmer, 2006) evidence suggests that $\mathrm{GABA}_{\mathrm{A}}$ and $\mathrm{GABA}_{\mathrm{C}}$ receptors are present at separate synapses. We have shown recently that lightevoked lateral IPSCs (L-IPSCs) at the Mb terminal consist of GABA and $\mathrm{GABA}_{\mathrm{C}}$ currents, which arise from pathway-specific $\mathrm{ON}$ or crossover OFF inputs (Vigh et al., 2011).

Short-term depression (STD) of reciprocal inhibition at $\mathrm{AC} \rightarrow \mathrm{BC}$ synapses is thought to modulate $\mathrm{BC}$ responses during high-frequency light stimulation (Li et al., 2007) and has been shown to prevent depression of excitatory ON cone $\mathrm{BC} \rightarrow \mathrm{GC}$ synapses in the mouse (Sagdullaev et al., 2011). However, the plasticity of L-IPSCs at the Mb terminal has not been explored previously. Here, we recorded directly from axotomized Mb terminals, which allowed us to quantify L-IPSCs in the absence of reciprocal feedback, and stimulated with pairs of full-field light flashes to characterize L-IPSC plasticity. We found that short- 

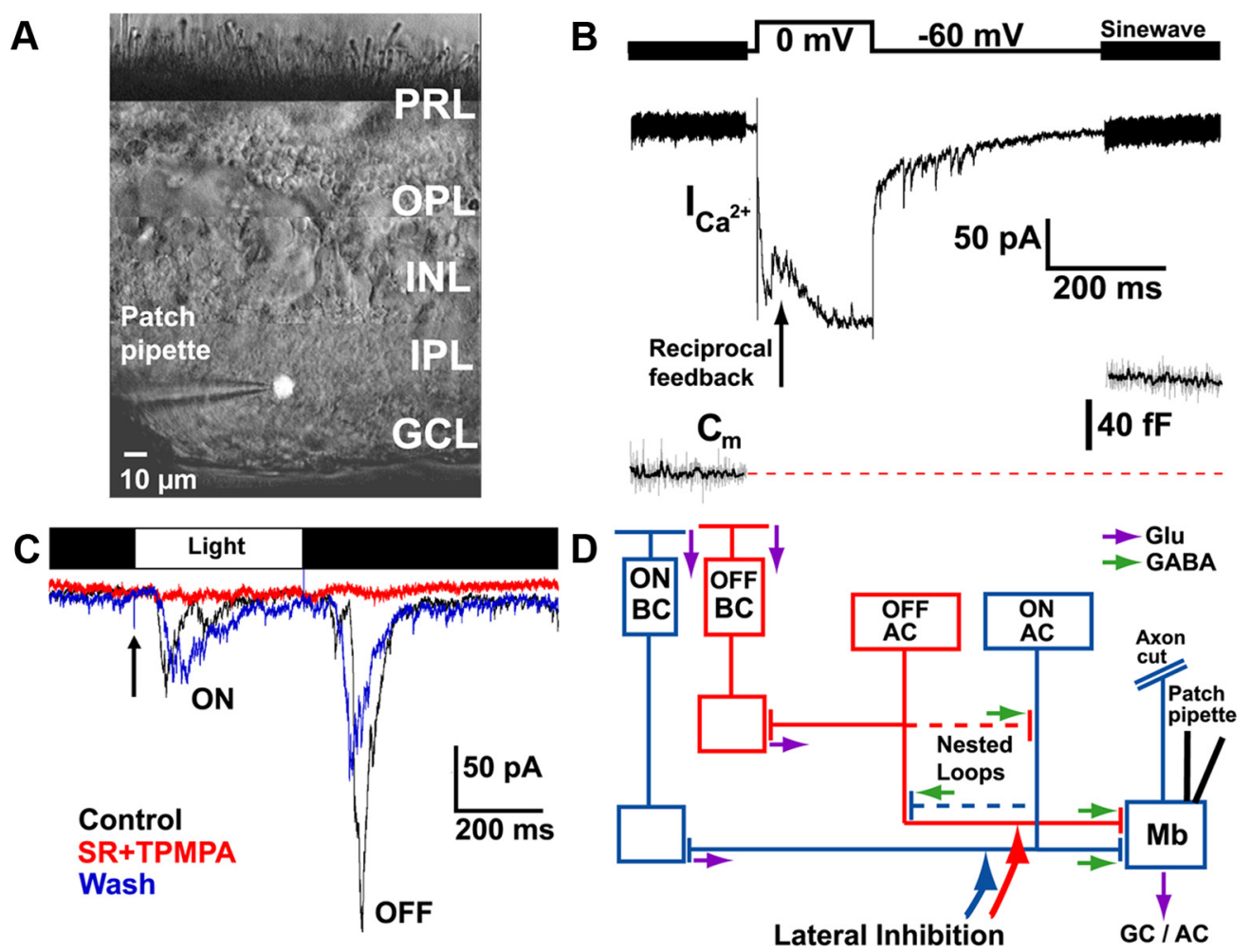

Figure 1. Light-evoked lateral inhibition in axotomized Mb BCs consists of distinct ON and OFF L-IPSCs that are mediated by GABA $A_{A}$ and GABA ${ }_{C}$ receptors. $A$, IR-DIC montage and epifluorescence overlay of whole-cell patch-clamp recording from an axotomized $\mathrm{Mb} B$ C presynaptic terminal in the innermost layer of the IPL. PRL, Photoreceptor layer; OPL, outer plexiform layer; INL, inner nuclear layer; $\mathrm{GCL}$, ganglion cell layer. $B$, Voltage-clamp recording of an axotomized $\mathrm{Mb} B C$ terminal revealed a large capacitance jump $\left(\Delta C_{\mathrm{m}}\right), \mathrm{Ca}^{2+}$ current $\left(I_{\mathrm{Ca}+}\right)$, and reciprocal feedback inhibition (arrow). Raw $C_{\mathrm{m}}$ measurements are shown in gray, and smoothed data are shown in black (bottom). $C$, Under dark-adapted, scotopic background conditions $\left(5.03 \times 10^{1}\right.$ photons $\left.\mu \mathrm{m}^{-2} \mathrm{~s}^{-1}\right)$, a 400-ms-duration, full-field light flash evoked distinct ON and OFF L-IPSCs (black trace; average of 20 stimulations). ON and 0FF L-IPSCs recorded after bath application of $25 \mu \mathrm{m}$ SR and $150 \mu \mathrm{m}$ TPMPA in the same cell are shown in red (average of 4 stimulations), and L-IPSCs obtained after washout of SR and TPMPA are shown in blue (average of 3 stimulations). The black arrow indicates a light flash stimulation artifact. $D$, Schematic of circuitry likely to underlie ON and OFF L-IPSCs recorded from the axotomized Mb BC terminal shown in C. The ON pathway (blue) travels across a trisynaptic pathway from rods and cones (data not shown) to a monostratified ON BC, to an ON AC, to the Mb BC terminal. ON ACs also provide "nested loop" feedback to OFF ACs via GABA $A_{A}$ synapses. The OFF pathway (red) follows either an indirect, multisynaptic route (disinhibitory: cones $\rightarrow O \mathrm{OFFC} \rightarrow O \mathrm{FF} \mathrm{AC} \rightarrow O \mathrm{NAC} \rightarrow \mathrm{Mb} \mathrm{BC}$ ) or a direct, trisynaptic route (inhibitory: cones $\rightarrow 0 \mathrm{FF} B C \rightarrow$ OFF AC $\rightarrow \mathrm{Mb} B C$ ) through a bistratified or diffuse AC. Glutamatergic synapse, purple arrow; GABAergic synapse, green arrow.

term plasticity (STP) differed for ON and OFF responses and was altered differentially by blockage of $\mathrm{GABA}_{\mathrm{A}}$ and $\mathrm{AMPA}$ receptors. Such dynamic regulation of lateral inhibition at BC terminals likely mediates rapid surround modulation and adaptation of GC and AC responses. We propose that STP of L-IPSCs acts to adjust the strength and spatial extent of postsynaptic AC and GC inhibitory surrounds by regulating both $\mathrm{Mb} \mathrm{BC}$ glutamate release during feedforward subthreshold depolarization (Joselevitch and Kamermans, 2007) and the ability of Mb terminals to initiate regenerative $\mathrm{Ca}^{2+}$ spikes (Zenisek and Matthews, 1998; Protti et al., 2000; Arai et al., 2010; Baden et al., 2011).

\section{Materials and Methods}

Retinal slice preparation and electrophysiology. Slices were prepared from pieces of goldfish (Carassius auratus; $8-14 \mathrm{~cm}$ ) retina, as described previously (Palmer et al., 2003). For experiments in which paired recordings of $\mathrm{ACs}$ and $\mathrm{Mb} \mathrm{BC}$ terminals were performed, the goldfish retina was gently removed from the eyecup and embedded in low-gellingtemperature agar $(3 \% \mathrm{w} / \mathrm{v}$ in slice solution; agarose type VII-A, A-0701; Sigma-Aldrich), as described by Kim et al. (2012). For all experiments, goldfish, of either sex, were dark adapted for $1-2 \mathrm{~h}$ before dissection, and slicing solution contained the following (in $\mathrm{mm}$ ): $119.0 \mathrm{NaCl}, 2.5 \mathrm{KCl}, 3.2$ $\mathrm{MgCl}_{2}, 0.3 \mathrm{CaCl}_{2}, 12.0$ glucose, 12.0 HEPES, and 0.2 ascorbic acid. The $\mathrm{pH}$ was set to 7.45 with $\mathrm{NaOH}$, and osmolarity was set to 260-265 mOsm. Dissection was performed under either dark or dim red light conditions, and recording was performed under either mesopic $(1.01 \times$ $10^{3}$ to $5.03 \times 10^{3}$ photons $\left.\mu \mathrm{m}^{-2} \mathrm{~s}^{-1}\right)$ or scotopic $\left(5.03 \times 10^{1}\right.$ photons $\mu \mathrm{m}^{-2} \mathrm{~s}^{-1}$ ) background conditions (Krizaj, 2000). Background light levels were measured with an ILT-1700 photometer and SE033 detector from International Light Technologies. Transverse slices ( $250 \mu \mathrm{m}$ thick) were cut with a Narishige ST-20 vertical slicer and transferred to a Sylgard (Dow Corning) recording chamber, in which they were secured in parallel lanes of petroleum jelly. For paired recordings, a diced agar block containing the retina was cut into $200-\mu \mathrm{m}$-thick slices using a Vibratome slicer (VT1000; Leica). The chamber and slices were then moved to an upright microscope (Axioskop; Carl Zeiss), in which the slices were constantly perfused with external recording solution bubbled with $95 \% \mathrm{O}_{2}$ and $5 \% \mathrm{CO}_{2}$ mixed gas at $4-5 \mathrm{ml} / \mathrm{min}$ and viewed with infrared differential interference contrast (IR-DIC) optics through a $40 \times$ waterimmersion objective (Carl Zeiss) coupled with 2.0 pre-magnification and an IR CCD camera (XC-75; Sony). The output of the CCD camera was sent to a Hamamatsu Camera Controller C2741-62 and then to a 13-inch Sony black and white monitor for viewing. Axotomized BC terminals (i.e., with severed axons) were identified in the IPL based on the following: (1) Mb-shaped (bulbous) terminal morphology (Fig. 1 A), (2) singleexponential membrane time constant (data not shown), and (3) the presence of an L-type $\mathrm{Ca}^{2+}$ current, reciprocal feedback, and $\Delta C_{\mathrm{m}}$ jump (Fig. 1 B; Palmer et al., 2003) associated with exocytosis (von Gersdorff and Matthews, 1999).

Axotomized BC terminals in retinal slices were voltage clamped at -60 or $-70 \mathrm{mV}$ (uncorrected for liquid junction potential) in the whole-cell mode using a HEKA Elektronik EPC-9 patch-clamp amplifier in conjunction with Pulse software running the xChart extension (Pulse version 8.53). The Sine +DC technique (Gillis, 2000) was used for real-time measurements of membrane capacitance. Briefly, a $30 \mathrm{mV}$ peak-to-peak, 
$1-2 \mathrm{kHz}$ sine wave was superimposed on the holding potential of the cells $(-60 \mathrm{mV})$ and used by online analysis software to calculate timeresolved membrane capacitance. Standard external recording solutions contained the following (in $\mathrm{mm}$ ): $100.0 \mathrm{NaCl}, 2.5 \mathrm{KCl}, 2.5 \mathrm{CaCl}_{2}, 1.0$ $\mathrm{MgCl}_{2}, 25.0 \mathrm{NaHCO}_{3}, 0.2$ ascorbic acid, and 12.0 glucose, $\mathrm{pH} 7.45$ (osmolarity, 260-265 mOsm). Patch pipettes (6-12 M 2 ) were pulled, either using a vertical (PP-830; Narishige) or horizontal (P-97; Sutter Instruments) puller, from thick-walled, 1.5-mm-outer-diameter borosilicate capillary glass from World Precision Instruments (1B150F-4) and coated with dental wax (Cavex) to reduce pipette capacitance. Internal pipette solutions contained the following solution (in mM): $60.0 \mathrm{Cs}$ gluconate, 40.0 CsCl, 10.0 TEA-Cl, 25.0 HEPES, 3.0 Mg-ATP, 0.5 Na-GTP, and 2.0 EGTA. Internal solutions for paired recordings contained 28.0 HEPES and 1.0 Na-GTP but were otherwise the same. Some internal solutions contained $3.0 \mathrm{~mm}$ ascorbic acid and/or $3.0 \mathrm{~mm}$ reduced glutathione. All internals were set to $\mathrm{pH} 7.2$ with $\mathrm{CsOH}$, and osmolarity was adjusted to $250 \mathrm{mOsm}$ with $\mathrm{Cs}$ gluconate and/or millipure $\mathrm{H}_{2} \mathrm{O}$. NBQX, TTX, TPMPA [(1,2,5,6-tetrahydropyridin-4-yl)methylphosphinic acid], and SR-95531 [6-Imino-3-(4-methoxyphenyl)-1(6H)-pyridazinebutanoic acid hydrobromide] (SR) were obtained from Tocris Bioscience. All other chemicals were obtained from Sigma.

Recordings were performed at $20-22^{\circ} \mathrm{C}$ during the daytime (morning/ afternoon) to avoid circadian variation in glutamate release from BCs (Hull et al., 2006b). Voltage-clamp series resistance $\left(R_{\mathrm{s}}\right)$ was not compensated, and liquid junction potential was not corrected. Cells with $R_{\mathrm{s}}>$ $30 \mathrm{M} \Omega$ or resting leak $>50 \mathrm{pA}$ at a holding potential of $-60 \mathrm{mV}$ were excluded from analysis. Average values for $R_{\mathrm{s}}$ and leak current at a holding potential of $-60 \mathrm{mV}$ were $22.0 \pm 1.2 \mathrm{M} \Omega$ and $-34.2 \pm 2.6 \mathrm{pA}$, respectively (mean \pm SE; $n=75$ ).

Light stimulation. Slices were stimulated with a white LED connected via soldered wire and BNC cable to a digital-to-analog output of the HEKA EPC-9 amplifier, as described previously (Vigh et al., 2011). The LED was positioned at an $\sim 30^{\circ}$ angle above and behind the recording chamber, at a distance of $3 \mathrm{~cm}$. Full-field light flashes for all experiments were delivered by application of voltage steps from 0 to between 3 and 5 $\mathrm{V}$, which evoked a photon flux at the slice of between $5.69 \times 10^{4}$ and $7.32 \times 10^{5}$ photons $\mu \mathrm{m}^{-2} \mathrm{~s}^{-1}$ (unless otherwise noted), which is above the threshold for cone photoreceptor activation $\left(\sim 10^{2}\right.$ photons $\mu \mathrm{m}^{-2}$ $\mathrm{s}^{-1}$; Busskamp et al., 2010). The timing and amplitude of voltage steps was controlled from within the Pulse Software (HEKA) running the EPC-9 amplifier. Calibration of light flash timing (onset and offset) was performed with a photodiode connected to the EPC- 9 amplifier through an ITHACO 4302 dual $24 \mathrm{~dB}$ octave filter. Light flash onset and offset had rise and decay time constants of 0.1 and $6.3 \mathrm{~ms}$, respectively. Onset and offset times did not vary as a function of flash duration between 100 and $1000 \mathrm{~ms}$ or with the presentation of paired flashes with intervals ranging from 300 to $1900 \mathrm{~ms}$. Calibration of light intensity was performed with an ILT-1700 photometer and SE033 detector from International Light Technologies. Factory calibration determined the photopic illuminance response sensitivity of the detector to be $2.60 \times 10^{-8} \mathrm{~A} \mathrm{ft}^{2} \mathrm{~lm}^{-1}$ or $2.415 \times 10^{-9} \mathrm{~A} \mathrm{lux}^{-1}$, assuming $3215 \mathrm{~K}$ color temperature.

Analysis of amplitude, charge, and onset latency of L-IPSCs. Light responses at each paired-pulse interval (PPI) were repeated at least five times per cell and averaged, unless otherwise stated. An interval of 20 or $30 \mathrm{~s}$ was presented between stimulations to allow for recovery from depression in neighboring $\mathrm{Mb}$ presynaptic terminals (von Gersdorff and Matthews, 1997). Under these conditions, light responses were generally stable for up to $30 \mathrm{~min}$. Nonetheless, stimulations with PPIs ranging from 50 to $2300 \mathrm{~ms}$ were interleaved to avoid systematic errors attributable to rundown. For PPIs shorter than $300 \mathrm{~ms}$, alternating single and double flashes were presented so that single responses could be subtracted from double responses. This allowed for isolation of the first OFF response and second $\mathrm{ON}$ response so that amplitude, charge transfer, and onset latencies could be reliably measured at short intervals (i.e., $50 \mathrm{~ms}$ ). L-IPSC amplitude was calculated by subtracting a baseline ON and OFF current (first $20 \mathrm{~ms}$ after onset and offset of light flash, respectively) from the peak current amplitude during the $400 \mathrm{~ms}$ light flash and the $300 \mathrm{~ms}$ after the offset of the light flash for ON and OFF responses, respectively. Charge transfer was calculated by integrating current traces during these $\mathrm{ON}(400 \mathrm{~ms})$ and OFF (300 ms) response windows after baseline subtraction.

L-IPSC onset latencies were determined using a custom IGOR procedure that detected the time at which the L-IPSC crossed a threshold current set at baseline minus 2 SDs, at which the baseline and SD were calculated from the $20 \mathrm{~ms}$ period at the beginning of either the $\mathrm{ON}$ or OFF response windows. The threshold crossing was determined by moving backward in time from the peak of the L-IPSC, which was detected as the global minima of the current recording during the response window. Latencies calculated with a similar technique in which the threshold was set at $10 \%$ of the difference between baseline and peak current were not significantly different from those calculated with the 2 SD criteria. Manual "by eye" detection of latencies also yielded comparable results but showed statistically significant underestimation of paired $\Delta$ onset latency compared with both the 2 SD criteria for ON L-IPSCs at the $300 \mathrm{~ms}$ PPI $(p<0.01$, unpaired Student's $t$ test, two tailed) and the $10 \%$ baseline to peak criteria at the $50 \mathrm{~ms}(p<0.05)$ and $300 \mathrm{~ms}(p<0.05)$ PPI. None of the three techniques showed significant differences for OFF L-IPSC latencies at either the 50 or $300 \mathrm{~ms}$ PPIs $(p>0.05)$. We report latencies using the $2 \mathrm{SD}$ criteria here because the results of this technique showed the fewest significant differences with the results of other techniques.

Immunohistochemistry and confocal imaging. During paired patchclamp recording, the $\mathrm{Mb}$ cell and $\mathrm{AC}$ were filled via the patch pipette with Alexa Fluor 555 and 488 hydrazide, respectively (100-200 $\mu$ m; Invitrogen). Immediately after the recording, retinal slices were transferred into $4 \%$ (w/v) paraformaldehyde in $1 \times$ PBS (catalog \#70013; Invitrogen) for 30 min. Slices were mounted onto Superfrost slides (Thermo Fisher Scientific) in aqueous mounting medium with GEL/MOUNT anti-fade solution (Biomeda). Alexa Fluor-containing $\mathrm{Mb} \mathrm{BCs}$ and $\mathrm{ACs}$ were viewed with laser lines at 488 and $555 \mathrm{~nm}$ using a $40 \times$ water-immersion objective on a confocal laser-scanning microscope (LSM 710; Carl Zeiss). Stacked confocal images were reconstructed with Imaris software (Bitplane Scientific Software).

DIC/epifluorescence overlays. During some recordings of single axotomized Mb terminals, the internal solution contained 150-200 $\mu \mathrm{M}$ Alexa Fluor 555 hydrazide. DIC montage images were recorded in iMovie (Apple) by connecting the Hamamatsu Camera Controller to a MacBook Pro (Apple) via a Dazzle Hollywood DV-Bridge frame grabber. Epifluorescence imaging was performed after recording by illumination of the preparation with an AttoArc HBO $100 \mathrm{~W}$ mercury lamp (Carl Zeiss). A filter cube matching the emission range of Alexa Fluor 555 was placed between the objective and the CCD camera. Fluorescence images were also acquired with iMovie and were later aligned with DIC montages using NIH ImageJ and Photoshop (Adobe Systems).

Statistical analyses. Statistics were performed on averaged traces, unless otherwise noted, by using Prism (version 4; GraphPad Software). Two-tailed paired or unpaired Student's $t$ tests were used to compare datasets when appropriate, and one-sample $t$ tests with a hypothetical mean of 0 or 1 were used to test paired-pulse plasticity of onset latency or size, respectively, at each PPI. Data were reported as mean \pm SEM, and values of $p<0.05$ were considered statistically significant.

\section{Results}

\section{Isolation of light-evoked GABAergic ON and OFF L-IPSCs at the Mb BC terminal}

To examine the synaptic properties of light-evoked lateral inhibition, we performed direct whole-cell voltage-clamp recordings of axotomized goldfish $\mathrm{Mb} \mathrm{BC}$ terminals (Fig. $1 A, B$ ). By recording with intracellular solution containing $40 \mathrm{mM} \mathrm{CsCl}$ and $10 \mathrm{~mm}$ TEA-Cl $\left(E_{\mathrm{Cl}}=-20.1 \mathrm{mV}\right)$ and voltage clamping the axotomized terminal at -60 or $-70 \mathrm{mV}$, we were able to evoke large inward L-IPSCs by stimulating the retinal slice with full-field, $400 \mathrm{~ms}$ duration, white light flashes (between $5.69 \times 10^{4}$ and $7.32 \times 10^{5}$ photons $\mu \mathrm{m}^{-2} \mathrm{~s}^{-1}$, unless otherwise noted; see Materials and Methods) under scotopic background conditions $\left(5.03 \times 10^{1}\right.$ photons $\mu \mathrm{m}^{-2} \mathrm{~s}^{-1}$; Fig. $1 C$ ). We refer to these events as L-IPSCs because they are expected to be inhibitory (or shunting) under 
Ai

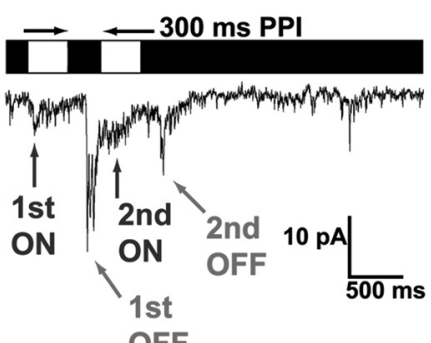

$\mathrm{Bi}$
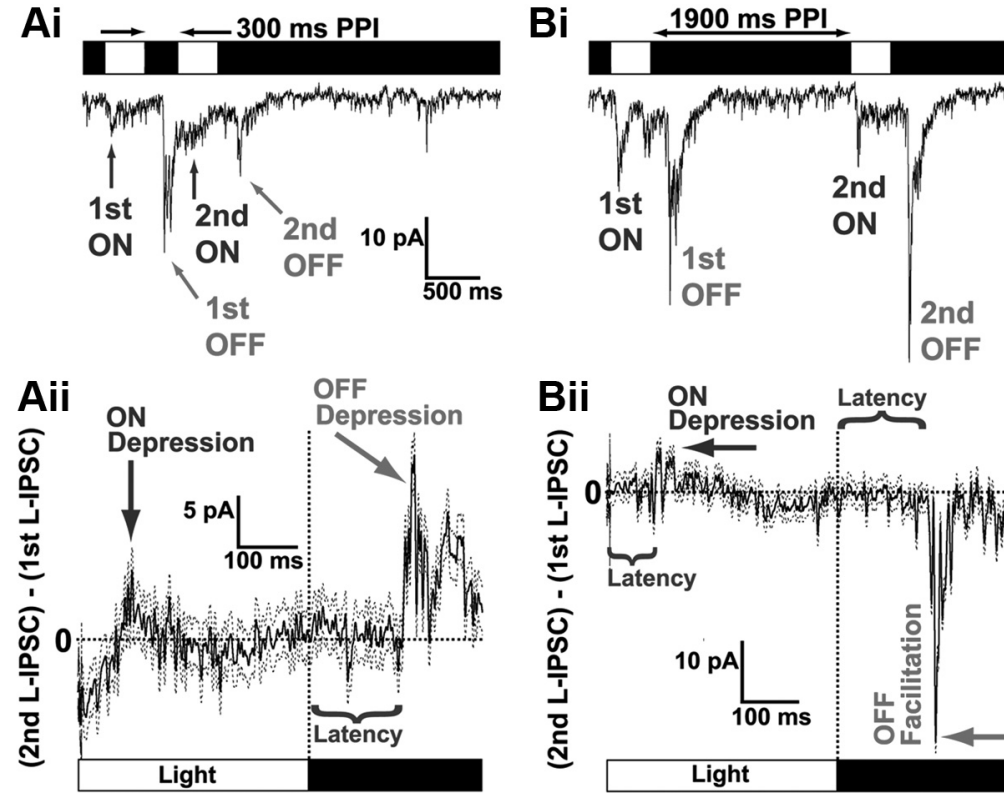

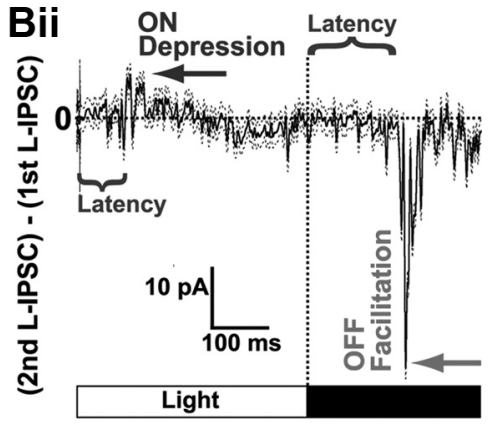

Figure 2. Light-evoked ON and OFF L-IPSCs exhibit STP in response to paired $400 \mathrm{~ms}$ full-field light flashes with PPIs between 50 and 1900 ms. ON L-IPSCs exhibited STD (second ON < first ON) at both short (300 ms; Ai) and long (1900 ms; Bi) intervals. OFF L-IPSCs exhibited STD (second OFF < first OFF) at short intervals ( $300 \mathrm{~ms} ; \boldsymbol{A i}$ ), and STF (second OFF $>$ first OFF) at long intervals (1900 ms; Bi). Traces shown are averages of five stimulations from a single cell. Aii, Bii, Windowed difference traces (second response - first response, \pm SD) of light-evoked example ON and OFF L-IPSCS from $\boldsymbol{A} \boldsymbol{i}$ and $\boldsymbol{B} \boldsymbol{i}$ show both depression and facilitation. STD of both ON and OFF L-IPSCS was evident as positive deflections during and after the light flash, respectively (indicated below), for the $300 \mathrm{~ms}$ PPI (Aii). At the $1900 \mathrm{~ms}$ PPI (Bii), ON STD was small, whereas OFF STF (negative deflection) was pronounced. Examples shown were recorded under mesopic background conditions $\left(5.03 \times 10^{3}\right.$ photons $\left.\mu \mathrm{m}^{-2} \mathrm{~s}^{-1}\right)$.

that then contacts either an ON diffuse or bistratified AC that makes direct synaptic contacts onto the Mb terminal. These indirect pathways, or nested loops of serial $\mathrm{AC} \rightarrow \mathrm{AC} \mathrm{GABA}_{\mathrm{A}}$ synapses (Fig. 1D, dashed lines; Marc and Liu, 2000; Hsueh et al., 2008), may be either homotypic (i.e., $\mathrm{ON} \rightarrow \mathrm{ON}$ or $\mathrm{OFF} \rightarrow \mathrm{OFF}$ ) or heterotypic (i.e., $\mathrm{ON} \rightarrow \mathrm{OFF}$ or $\mathrm{OFF} \rightarrow \mathrm{ON}$ ) and have been shown to regulate the strength of BC inhibitory surrounds (Eggers and Lukasiewicz, 2010).

\section{ON and OFF L-IPSCs exhibit different temporal profiles of STP}

To determine the likely effects of dynamic surround stimulation on the size and timing of lateral feedback inhibition at the $\mathrm{Mb}$ terminal, we tested STP of L-IPSCs over the PPI range of 50-2300 ms. Here, PPI refers to the interval between the offset of the first light flash and the onset of the second light flash. Short PPIs (e.g., 300 ms; Fig. 2Ai) tended to produce STD of ON and OFF L-IPSC amplitude ( 20\%) and charge $(\sim 15 \%)$, whereas long PPIs (e.g., $1900 \mathrm{~ms}$; Fig. $2 \mathrm{Bi}$ ) tended to produce STD of ON L-IPSC amplitude and charge (10-15\%) and short-term facilitation (STF) of OFF L-IPSC amplitude $(\sim 25 \%)$. Subtraction of the first light re-

physiological conditions. Previous studies have estimated $E_{\mathrm{Cl}}$ at the $\mathrm{BC}$ terminal to be between -42 and $-60 \mathrm{mV}$ (Billups and Attwell, 2002; Duebel et al., 2006), with a resting membrane potential $\left(E_{\mathrm{m}}\right)$ of between -40 and $-53 \mathrm{mV}$ (Protti et al., 2000; Wong et al., 2005; Baden et al., 2011).

The control light response (Fig. 1C, black trace) consisted of distinct ON ( $\sim 50 \mathrm{~ms}$ latency) and OFF L-IPSCs $(\sim 100 \mathrm{~ms}$ latency), which could both be blocked completely by bath application of $25 \mu \mathrm{M}$ SR and $150 \mu \mathrm{M}$ TPMPA (Fig. $1 C$, red trace). Similar results were obtained with $12.5 \mu \mathrm{M}$ SR (data not shown), a concentration less likely to produce significant nonspecific block of glycine receptors (GlyRs; Wang and Slaughter, 2005). This block was reversible during washout (Fig. $1 C$, blue trace). This result confirmed our previous findings that both ON and OFF L-IPSCs at the $\mathrm{Mb}$ terminal consist entirely of $\mathrm{GABA}_{\mathrm{A}}$ and $\mathrm{GABA}_{\mathrm{C}}$ receptor-mediated responses and are not mediated by GlyRs (i.e., not blocked by $1 \mu \mathrm{M}$ strychnine; Vigh et al., 2011).

In Figure $1 D$, we show a schematic of the patterns of connectivity that are likely responsible for propagation of $\mathrm{ON}$ and crossover OFF lateral inhibition from the dendrites of neighboring or distant $\mathrm{ON}$ and OFF BCs to the Mb terminal. ON lateral inhibition is driven by mixed rod and cone inputs (Vigh et al., 2011) and arrives via a direct trisynaptic pathway that passes through neighboring ON BCs and ON ACs. However, OFF lateral inhibition is primarily driven by cone inputs (Vigh et al., 2011) and travels via either a direct trisynaptic pathway or an indirect, disinhibitory multisynaptic pathway (Fig. 1D). The direct pathway likely consists of an input from an OFF BC to an OFF AC that forms synaptic contacts onto the $\mathrm{Mb}$ axon shaft or an input from an OFF BC to a bistratified or diffuse AC that makes synaptic contacts directly onto the $\mathrm{Mb}$ terminal. The indirect OFF pathway could arise from an OFF BC via contacts onto an OFF AC sponse (both ON and OFF components; windowed from $t=0 \mathrm{~ms}$ at light onset to $t=700 \mathrm{~ms}$ at termination of OFF response; $\mathrm{ON}$ response ends at $t=400 \mathrm{~ms}$, OFF response begins at $t=400 \mathrm{~ms}$ ) from the second light response of the pair yielded difference traces that showed clear STD of ON and OFF L-IPSCs at a PPI of $300 \mathrm{~ms}$ (Fig. 2 Aii; same cell as Ai), and a combination of ON STD and OFF STF at a PPI of $1900 \mathrm{~ms}$ (Fig. 2 Bii; same cell as Bi). Note that, for the $300 \mathrm{~ms}$ interval, ON STD in the difference trace is seen as a positive deflection relative to a baseline with an initial negative offset attributable to incomplete decay of the first OFF L-IPSC (Fig. 2Aii). For this reason, STP at the $50 \mathrm{~ms}$ PPI was determined with a protocol of alternating single and double light flashes. This allowed for the isolation of first and second $\mathrm{ON}$ and OFF L-IPSCs by subtraction of the single response from the double response (see Materials and Methods).

$\mathrm{ON}$ and OFF L-IPSCs showed different temporal profiles of amplitude (Fig. 3A) and charge transfer STP (Fig. 3B). STP of both amplitude and charge transfer were quantified as pairedpulse ratios (PPRs), and depression or facilitation were defined as PPRs that were $<1$ or $>1$, respectively (Fig. 3, gray asterisks). In addition, we performed direct statistical comparisons between ON and OFF PPRs at each PPI (Fig. 3, black asterisks). ON L-IPSC amplitude depression was highly statistically significant at PPIs of $50 \mathrm{~ms}(\mathrm{PPR}=0.57 \pm 0.05 ; n=14$; $p<0.001$, onesample $t$ test $)$ and $300 \mathrm{~ms}(0.78 \pm 0.06 ; n=34 ; p<0.001)$ recovered at $1100 \mathrm{~ms}(p>0.05)$ and showed small but significant depression at $1900 \mathrm{~ms}(0.87 \pm 0.04 ; n=39 ; p<0.01)$ that recovered by $2300 \mathrm{~ms}$. In contrast, OFF amplitude depression was sometimes strong at a PPI of $50 \mathrm{~ms}$, although high variability at this short PPI prevented the depression from reaching statistical significance $(\mathrm{PPR}=0.94 \pm 0.16 ; n=6 ; p>0.05)$. OFF depression was present at $300 \mathrm{~ms}(0.82 \pm 0.07 ; n=32 ; p<0.05)$ 
but was replaced by facilitation at $1100 \mathrm{~ms}$ $(1.21 \pm 0.10 ; n=32 ; p<0.05)$ that continued at $1900 \mathrm{~ms}(1.26 \pm 0.09 ; n=37$; $p<0.01$ ) before recovery at $2300 \mathrm{~ms}$. ON L-IPSCs were significantly depressed relative to OFF L-IPSCs at PPIs of $50 \mathrm{~ms}$ $(\Delta \mathrm{PPR}=-39.4 \% ; p<0.01)$ and $1900 \mathrm{~ms}$ $(\Delta \mathrm{PPR}=-30.6 \% ; p<0.001$, unpaired Student's $t$ test, two tailed). These differences in the STP profiles of ON and OFF L-IPSC amplitude likely allow them to act as independent temporal filters on the early and late phases, respectively, of light responses at $\mathrm{Mb}$ terminals. When taken together, they suggest a mechanism for regulation of the balance between surround temporal contrast adaptation (i.e., OFF facilitation) and sensitization (i.e., ON and OFF depression) at $\mathrm{Mb} \rightarrow \mathrm{GC}$ and $\mathrm{Mb} \rightarrow \mathrm{AC}$ inputs. This balance is likely adaptive during rapid transitions between visual environments containing high and low contrast (Kastner and Baccus, 2011).

Next, we analyzed the total integrated charge transfer of baseline-subtracted ON and OFF L-IPSCs (Fig. 3B). ON L-IPSC charge transfer exhibited strong depression at a PPI of $50 \mathrm{~ms}$ $(\mathrm{PPR}=0.39 \pm 0.08 ; n=14 ; p<0.001$, one-sample $t$ test $)$. This depression recovered at $300 \mathrm{~ms}$, and small but significant depression reemerged at PPIs of $1100 \mathrm{~ms}(0.78 \pm 0.08 ; n=34 ; p<0.05)$ and $1900 \mathrm{~ms}(0.79 \pm 0.06 ; n=39 ; p<0.01)$. ON depression was not significant at $2300 \mathrm{~ms}$. OFF charge transfer STP (Fig. 3B) followed a time course of recovery from depression that was similar to that of the $\mathrm{ON}$ response, with strong depression at $50 \mathrm{~ms}$ $(\mathrm{PPR}=0.47 \pm 0.20 ; n=6 ; p<0.05)$, recovery at $300 \mathrm{~ms}$, moderate depression at $1100 \mathrm{~ms}(0.78 \pm 0.06 ; n=32 ; p<0.001)$, and recovery at 1900 and $2300 \mathrm{~ms}$ PPIs. Similarly to the result for amplitude PPR, ON L-IPSCs were significantly depressed relative to OFF L-IPSCs at the $1900 \mathrm{~ms}$ PPI $(\Delta \mathrm{PPR}=-24.9 \% ; p<0.05$, unpaired Student's $t$ test, two tailed).

\section{ON and OFF L-IPSCs exhibit differential onset latency STP}

Interestingly, ON and OFF L-IPSCs also exhibited distinct STP of onset latency (Fig. 4). Such changes in the timing of presynaptic lateral inhibition may strongly determine the degree to which L-IPSCs inhibit or shunt light-evoked EPSPs (Oltedal et al., 2009) or light-evoked $\mathrm{Ca}^{2+}$ action potentials (Protti et al., 2000) at the $\mathrm{Mb}$ BC terminal, whether ACs act to either inhibit or disinhibit GC spiking (Manu and Baccus, 2011), and whether L-IPSCs primarily shape BC representations of either temporal contrast or mean luminance (Oesch and Diamond, 2011). To quantify the STP of onset latency, we first identified ON and OFF L-IPSC onset latencies as the crossing point of a threshold defined as baseline current minus 2 SDs of the baseline, working backward from the peak of the L-IPSC toward the beginning of the response window (see Materials and Methods; Fig. 4Ai,Aii, vertical dotted lines).

We found that ON and OFF L-IPSCs exhibited different forms of onset latency plasticity. ON L-IPSCs showed a strong pairedpulse delay (i.e., increase) in onset latency (Fig. $4 A i, B i$, blue) at PPIs of $50 \mathrm{~ms}$ ( $\Delta$ onset latency $=+75.0 \pm 28.3 \mathrm{~ms} ; n=9 ; p<$ 0.05 , one-sample $t$ test, green asterisks) and $300 \mathrm{~ms}(+34.0 \pm$ $11.3 \mathrm{~ms} ; n=34 ; p<0.01)$. These effects were large relative to the mean onset latency of the first L-IPSCs of each pair (50 ms PPI, $+96.0 \pm 38.6 \%$; $300 \mathrm{~ms}$ PPI, +60.2 \pm 18.3\%; Fig. 4 Bii). ON onset latency STP was not significant at PPIs of 1100 and $1900 \mathrm{~ms}$ (data not shown). This delay of ON L-IPSCs at short PPIs may be caused by depletion of the readily releasable vesicle pool at $\mathrm{ON}$ BC ribbon synapses (von Gersdorff and Matthews, 1997), which would result in a strong reduction of the initial, fast component of glutamate release onto AC dendrites.

OFF L-IPSCs, which may be mediated by a class of ACs with release properties that are different from those of the ACs that mediate ON L-IPSCs (Vigh et al., 2011), showed paired-pulse advances (i.e., decreases) in onset latency at short PPIs. OFF onset latency (300 ms PPI example; Fig. 4Aii) showed a significant advance at the $300 \mathrm{~ms}$ PPI ( $\Delta$ onset latency $=-29.8 \pm 10.1 \mathrm{~ms}$; $n=31 ; p<0.01$, one-sample $t$ test; Fig. $4 B i$, red). There was no significant onset latency STP of OFF L-IPSCs at the $50 \mathrm{~ms}$ PPI $(+5.4 \pm 3.2 \mathrm{~ms} ; n=5 ; p>0.05)$ or at the 1100 and $1900 \mathrm{~ms}$ PPIs (data not shown). When normalized to first L-IPSC latencies, OFF $\Delta$ onset latency was relatively modest (50 ms PPI, $+5.0 \pm$ $3.8 \%$; 300 ms PPI, $-13.9 \pm 5.8 \%$; Fig. 4 Bii). Importantly, OFF $\Delta$ onset latency was significantly different from ON $\Delta$ onset latency at both the $50 \mathrm{~ms}(\mathrm{ON}-\mathrm{OFF} \Delta$ onset latency $=+63.8 \pm 15.2 \mathrm{~ms}$; $p<0.0001$, unpaired Student's $t$ test, two tailed; Fig. 4 Bi, purple asterisks) and $300 \mathrm{~ms}$ PPIs (ON-OFF $\Delta$ onset latency $=+69.5 \pm$ $28.5 \mathrm{~ms} ; p<0.05)$. There was no significant difference in $\Delta$ onset latency between scotopic (Fig. $4 \mathrm{Bi}$, open circles) or mesopic (Fig. $4 \mathrm{Bi}$, filled circles) background conditions at the $300 \mathrm{~ms}$ PPI for ON L-IPSCs (scotopic, +44.6 $\pm 27.1 \mathrm{~ms}, n=11$; mesopic, $+28.9 \pm 10.9 \mathrm{~ms}, n=23 ; p=0.52$, unpaired Student's $t$ test, two tailed), although there was a nonsignificant trend toward larger $\Delta$ onset latencies for OFF L-IPSCs under mesopic background (scotopic, $+4.6 \pm 27.1 \mathrm{~ms}, n=5$; mesopic, $-36.5 \pm 11.0 \mathrm{~ms}, n=26$; $p=0.14)$.

\section{ON and OFF L-IPSC size and timing differentially adapt to background light}

Feedforward light responses in the intact $\mathrm{Mb}$ terminal consist of either analog EPSPs with an onset latency of $\sim 35-50 \mathrm{~ms}$ under mesopic background conditions (Wong et al., 2005) or a combination of EPSPs and $\mathrm{Ca}^{2+}$ action potentials with onset latencies ranging from 50-100 ms (Joselevitch and Kamermans, 2007) or 75-90 ms (Protti et al., 2000; Baden et al., 2011), respectively, under scotopic background conditions. Therefore, the functional interpretation of ON and OFF L-IPSC size and latency STP requires examination of the degree to which changes in the absolute size and latency of single responses is influenced by background light. Furthermore, the degree to which ON and OFF L-IPSCs overlap or act independently at the $\mathrm{Mb}$ terminal during exposure to rapidly changing naturalistic visual stimuli will depend on the differ- 

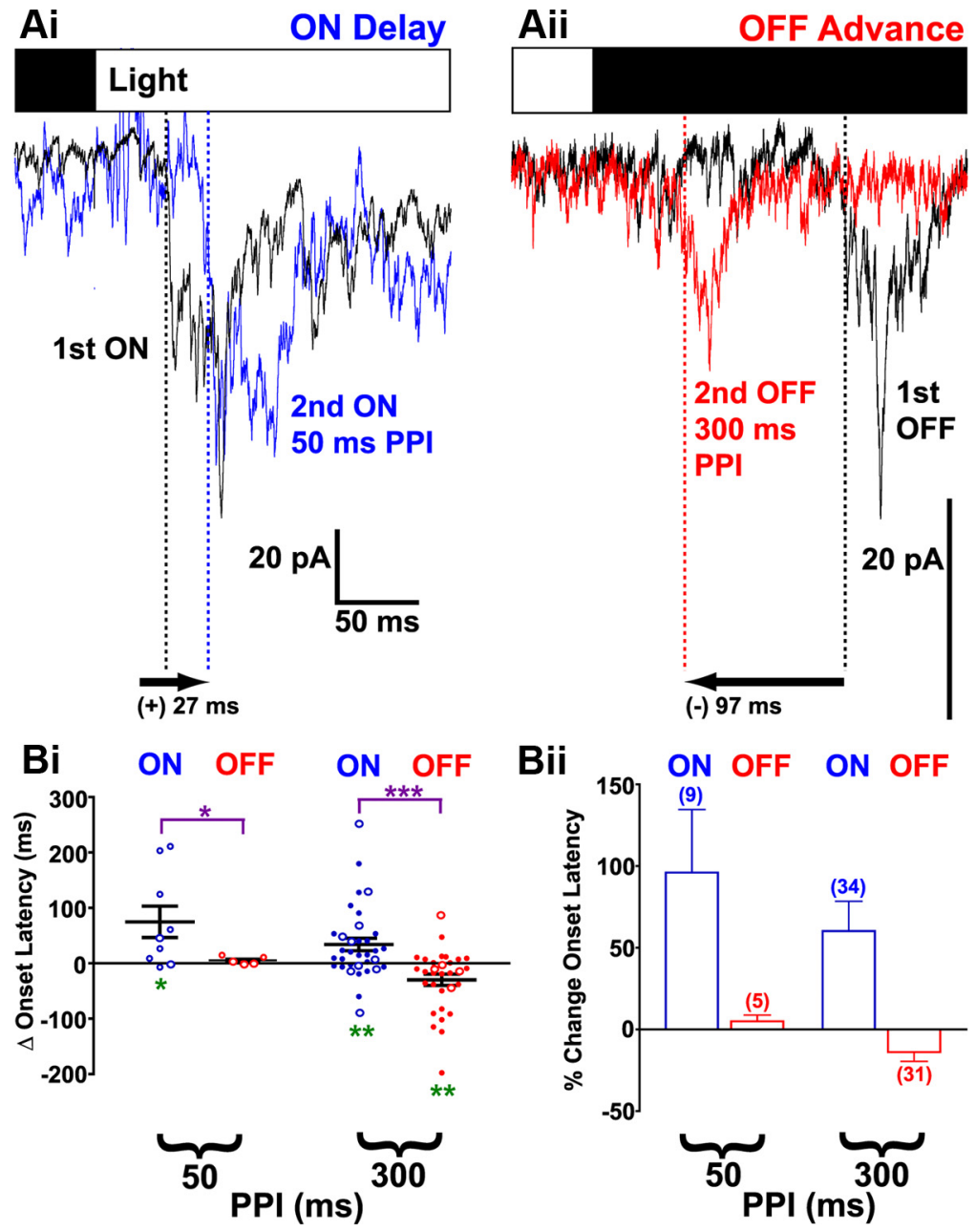

Figure 4. Light-evoked ON and OFFL-IPSCs exhibit differential STP of onset latency. Ai, Direct overlay of first (black) and second (blue) ON L-IPSCs at a PPI of $50 \mathrm{~ms}$ (left) showed a $27 \mathrm{~ms}$ delay (increase) of onset latency in an example cell recorded under scotopic background $\left(5.03 \times 10^{1}\right.$ photons $\left.\mu \mathrm{m}^{-2} \mathrm{~s}^{-1}\right)$. Aii, Direct overlay of first (black) and second (red) OFF L-IPSCs at a PPI of $300 \mathrm{~ms}$ (left) showed a $97 \mathrm{~ms}$ advance (decrease) of onset latency in an example cell (different cell from Ai) recorded under mesopic background $\left(5.03 \times 10^{3}\right.$ photons $\mu \mathrm{m}^{-2} \mathrm{~s}^{-1}$ ). Bi, Overall $\Delta$ onset latencies (= onset latency of second response - onset latency of first response) are shown for ON (blue) and OFF (red) L-IPSCs at the $50 \mathrm{~ms}$ (left) and $300 \mathrm{~ms}$ (right) PPIs. Data at each PPI were tested againsta null $\Delta$ onset latency $=0$ (delay $>0 \mathrm{~ms}$, advance $<0 \mathrm{~ms}$; green asterisks), and $0 \mathrm{~N}$ and $0 \mathrm{FF} \Delta$ onset latencies were directly compared at each PPI (purple brackets, asterisks). Filled circles indicate mesopic background; open circles indicate scotopic background. All traces shown are averages of at least five stimulations. ${ }^{*} p<0.05$, ${ }^{* *} p<0.01$, ${ }^{* * *} p<0.0001$. Bii, Normalized data [( $\Delta$ onset latency/onset latency of first L-IPSC) $\times 100$; same cells as Bi)] are shown for 0 N (blue) and OFF (red) L-IPSCs at each PPI. Number of cells $(n)$ in each condition is indicated in parentheses (same as $B i$ ). Error bars are mean \pm SE.

cause of enhancement of voltage-gated $\mathrm{Na}^{+}$ channel conductances in cone BCs after a putative reduction of dopaminergic signaling (Zenisek et al., 2001; Ichinose and Lukasiewicz, 2007).

Consistent with these expectations, the amplitudes of ON (scotopic background, $45.4 \pm 6.5 \mathrm{pA}, n=20$; mesopic background, $29.6 \pm 3.7 \mathrm{pA}, n=20 ; p<0.05$, unpaired Student's $t$ test, two tailed; Fig. $5 B$, top left) and OFF (scotopic background, $34.9 \pm 5.5$ pA, $n=18$; mesopic background, $20.5 \pm 2.6$ $\mathrm{pA}, n=18$; $p<0.05$; Fig. $5 B$, top right) L-IPSCs under scotopic background were larger than under mesopic background. There was no significant dependence of $\mathrm{GABA}_{\mathrm{C}} \mathrm{R}$-mediated standing leak current (Hull et al., 2006a) on background light (scotopic, $-28.3 \pm 3.0 \mathrm{pA}, n=20$; mesopic, $-27.8 \pm 3.1 \mathrm{pA}, n=20 ; p=0.90$, unpaired Student's $t$ test, two tailed). ON L-IPSC latency showed the expected delay (i.e., increase) after the transition to scotopic background (scotopic, $75.6 \pm 7.4 \mathrm{~ms}, n=20$; mesopic, $52.4 \pm 2.6 \mathrm{~ms}, n=20$; $p<0.01$; Fig. $5 B$, bottom left). However, OFF L-IPSC latency surprisingly showed a significant advance (i.e., decrease; scotopic background, $68.7 \pm$ $7.5 \mathrm{~ms}, n=18$; mesopic background, $146.7 \pm 12.3 \mathrm{~ms}, n=15 ; p<0.0001$; Fig. $5 B$, bottom right). This decreased latency of OFF L-IPSCs, which are driven primarily by the light responses of cone photoreceptors (Vigh et al., 2011), may have been attributable to acceleration of glutamate release from cone BC terminals caused by enhanced $\mathrm{Na}^{+}$channel amplification of cone $\mathrm{BC}$ responses under scotopic background (Ichinose et al., 2005; Ichinose and Lukasiewicz, 2007).

These experiments do not exclude the possibility that background light may have caused these changes in OFF L-IPSC latencies via light-dependent changes in voltagegated $\mathrm{Na}^{+}$channel amplification of OFF AC EPSPs (Vigh et al., 2011). Interestingly,

ence between their onset latencies under different background illumination. To test the sensitivity of L-IPSC amplitude and onset latency to light adaptation state, we varied background light intensity from scotopic $\left(5.03 \times 10^{1}\right.$ photons $\left.\mu \mathrm{m}^{-2} \mathrm{~s}^{-1}\right)$ to mesopic $(5.03 \times$ $10^{3}$ photons $\mu \mathrm{m}^{-2} \mathrm{~s}^{-1}$ ) levels (Fig. 5 ).

Mixed rod/cone-mediated ON L-IPSCs (Vigh et al., 2011) were expected to show delayed (i.e., increased) onset latencies when background light was shifted from mesopic to scotopic levels (Fig. $5 \mathrm{~A}$ ) as a result of an increased relative contribution of slow rod inputs via mGluR6 (Wong et al., 2005). In addition, ON L-IPSCs were expected to increase in amplitude under scotopic background conditions as a result of increased recruitment of rods (Wong et al., 2005; Vigh et al., 2011) and decreases in both L-type $\mathrm{Ca}^{2+}$ channel inactivation and steady-state depletion of the readily releasable vesicle pool (Jarsky et al., 2011; Oesch and Diamond, 2011) in neighboring $\mathrm{Mb}$ terminals. Cone-dominant OFF L-IPSCs were also expected to increase in amplitude under scotopic background be- the advance of OFF L-IPSCs under scotopic background resulted in the elimination of the significant differences in $\mathrm{ON}$ versus OFF onset latency that we observed under mesopic background (mesopic, OFF-ON latency, $+94.4 \pm 12.0 \mathrm{~ms}, p<0.0001$, unpaired Student's $t$ test, two tailed; scotopic, OFF-ON latency, $-6.8 \pm 10.8 \mathrm{~ms}, p>$ $0.05)$. Thus, ON and OFF L-IPSCs evoked in response to naturalistic stimuli containing rapid fluctuations in surround luminance would be expected to significantly overlap with each other under scotopic background and to remain temporally distinct under mesopic (or photopic) background light levels.

\section{Contribution of feedback inhibition and serial inhibitory circuits to STP of ON and OFF L-IPSCs}

To explore the mechanisms that underlie differential STP of ON and OFF L-IPSCs, we used a pharmacological approach to dissect the roles of circuits that mediate horizontal cell (HC) $\rightarrow$ photoreceptor $(\mathrm{PR})$ feedback inhibition in the outer retina (Fahrenfort 
et al., 2005, 2009) and AC $\rightarrow$ AC serial inhibition in the inner retina (i.e., "nested loops," Fig. 1D; Zhang et al., 1997; Watanabe et al., 2000; Hsueh et al., 2008; Eggers and Lukasiewicz, 2010). Block of these circuits would be expected to increase the dynamic range of $\mathrm{ON}$ and $\mathrm{OFF}$ $\mathrm{BC}$ voltage responses to light stimulation and to disinhibit ACs that mediate the direct pathway for L-IPSCs (Fig. 1D), respectively. Thus, we hypothesized that functional removal of these outer and inner retinal subcircuits would result in the enhancement of vesicle depletion at $\mathrm{AC}$ (Li et al., 2007) and BC (von Gersdorff and Matthews, 1997) presynaptic terminals at different locations in the trisynaptic circuits that mediate $\mathrm{ON}$ and $\mathrm{OFF}$ L-IPSCs and thus differentially shape light-evoked depression and facilitation.

First, we examined the effect of AMPAR blockade on STP of ON L-IPSC charge transfer by bath applying $10 \mu \mathrm{M}$ NBQX (Fig. 6A, blue). We showed previously that ON L-IPSC propagation at ON $\mathrm{BC} \rightarrow$ AC synapses can occur in the absence of AMPAR signaling and that block of AMPARs both eliminates OFF L-IPSCs and enhances ON L-IPSC charge transfer at the $\mathrm{Mb}$ terminal, likely via block of $\mathrm{HC}$ $\rightarrow$ PR feedback inhibition (Vigh et al., 2011). Previous studies have demonstrated that this feedback is activated by PR release of glutamate onto AMPA receptors on HCs in the dark, followed by $\mathrm{HC}$ depolarization and either $\mathrm{pH}$ mediated or ephaptic inhibition of $\mathrm{Ca}^{2+}$ channels on PR terminals (Fahrenfort et al., 2005, 2009). Our examination of STP in the presence of NBQX (Fig. 6C, left, blue) revealed that ON L-IPSCs exhibited strong depression of charge transfer at the $300 \mathrm{~ms}$ PPI (PPR, $0.19 \pm 0.04 ; n=6 ; p<0.0001$, one-sample $t$ test; green asterisks) that recovered at PPIs of 1100 and 1900 ms. Depression in the presence of NBQX at the $300 \mathrm{~ms}$ PPI was significantly enhanced relative to control ( $p<0.0001$, unpaired Student's $t$ test with Welch's correction; same control data as Fig. $3 B$, purple asterisks).

Next, we tested the effects of blocking $\mathrm{GABA}_{\mathrm{A}} \mathrm{Rs}$ on $\mathrm{ON}$ and OFF STP over a range of PPIs from 50 to $1900 \mathrm{~ms}$. Bath application of $25 \mu \mathrm{M} \mathrm{SR}$, which blocks $\mathrm{GABA}_{\mathrm{A}}$ Rs at reciprocal $\mathrm{AC} \rightarrow \mathrm{Mb}$ (Vigh and von Gersdorff, 2005) and serial AC $\rightarrow$ AC (Dowling and Werblin, 1969; Zhang et al., 1997; Watanabe et al., 2000; Eggers and Lukasiewicz, 2010) synapses, caused a clear disinhibition of both ON and OFF L-IPSCs (Fig. 6 B, red; Vigh et al., 2011). In the presence of $S R, O N$ depression was not significantly altered relative to control PPRs (Fig. 6C, middle; same control data as Fig. 3B), except that depression at the $1900 \mathrm{~ms}$ PPI was not significant with SR (PPR, $0.92 \pm 0.07 ; n=26 ; p>0.05$, one sample $t$ test). However, STP of OFF L-IPSC charge transfer (Fig. $6 C$, right) and peak amplitude (data not shown) were transformed in the presence of SR. Depression of OFF charge transfer was signif- icantly reduced relative to control at the $300 \mathrm{~ms}$ PPI (control PPR, $0.87 \pm 0.07, n=32$; SR PPR, $1.20 \pm 0.12, n=20 ; p<0.01$, unpaired Student's $t$ test, two tailed), and facilitation of OFF peak amplitude was significantly reduced at PPIs of $1100 \mathrm{~ms}$ (control PPR, $1.21 \pm 0.10, n=32$; SR PPR, $0.80 \pm 0.10, n=18 ; p<0.01)$ and $1900 \mathrm{~ms}$ (control PPR, $1.26 \pm 0.09, n=37$; SR PPR, $0.84 \pm$ 0.06, $n=18$; $p<0.01)$.

Any potential contribution of $\mathrm{GABA}_{\mathrm{A}} \mathrm{R}$ desensitization to total depression was eliminated by bath application of $S R$, because $\mathrm{GABA}_{\mathrm{C}}$ Rs do not exhibit desensitization (Matthews et al., 1994; Lukasiewicz et al., 2004). Therefore, these results are consistent with the idea that $\mathrm{GABA}_{\mathrm{A}} \mathrm{R}$ desensitization at lateral $\mathrm{AC} \rightarrow \mathrm{Mb}$ synapses may contribute to OFF depression, but not ON depression, at short PPIs. In addition, SR block of OFF peak amplitude facilitation at long intervals suggested that $\mathrm{GABA}_{\mathrm{A}}$-mediated signaling at serial $\mathrm{AC} \rightarrow \mathrm{AC}$ synapses may act primarily to regulate STP at AC terminals that mediate OFF, but not ON, L-IPSCs. However, ON depression, which remained intact after $\mathrm{GABA}_{\mathrm{A}} \mathrm{R}$ blockade, may depend primarily on a distinct mechanism, such as vesicle depletion at $\mathrm{AC} \rightarrow$ $\mathrm{Mb} \mathrm{GABA}_{\mathrm{C}} \mathrm{R}$ synapses. 
A

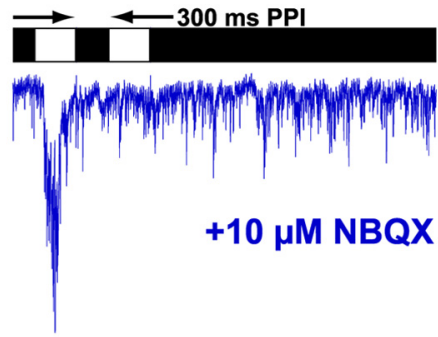

B
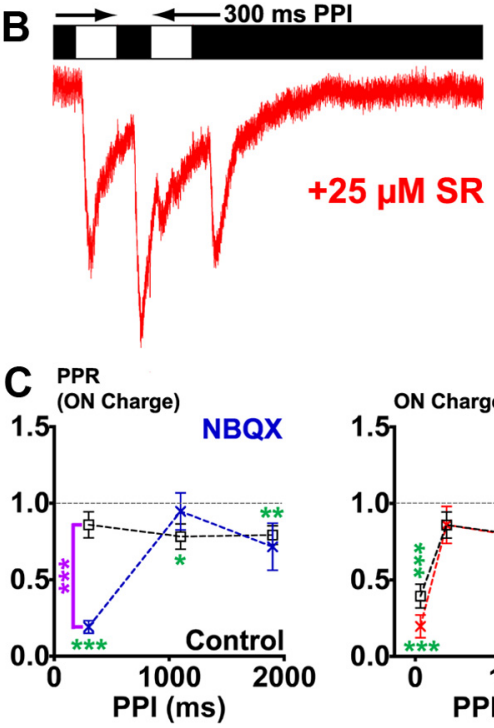
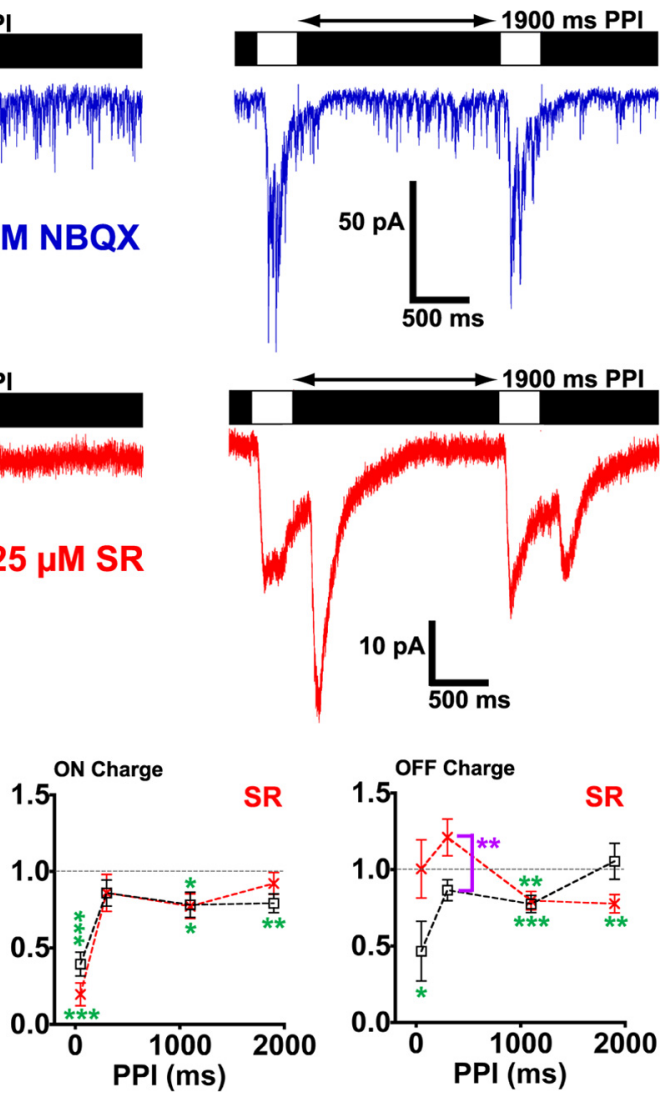

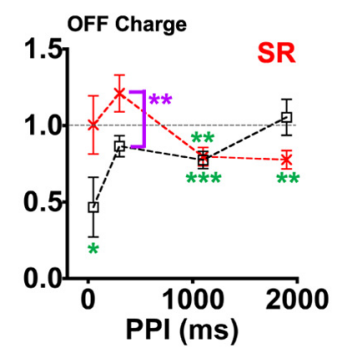

Figure 6. Block of signaling at AMPA receptors enhances STD of ON L-IPSC, whereas block of signaling at GABA receptors reduces STD of OFFL-IPSCS. $A$, In an example cell recorded under scotopic background $\left(5.03 \times 10^{1}\right.$ photons $\left.\mu \mathrm{m}^{-2} \mathrm{~s}^{-1}\right)$, block of AMPARs with $10 \mu \mathrm{M}$ NBQX resulted in near complete STD of ON L-IPSCs at the $300 \mathrm{~ms}$ PPI (left). This ON STD was nearly completely recovered at the PPI of $1900 \mathrm{~ms}$ (right). Traces shown (blue) are averages of five stimulations. Light flashes are indicated by white rectangles above traces. $\boldsymbol{B}$, Block of $\mathrm{GABA}_{\mathrm{A}} \mathrm{Rs}$ with $25 \mu \mathrm{m}$ SR revealed purely GABA $\mathrm{R}$-mediated L-IPSCs. In an example cell (different cell from $A$ ) recorded under mesopic background $\left(5.03 \times 10^{3}\right.$ photons $\left.\mu \mathrm{m}^{-2} \mathrm{~s}^{-1}\right), 0 \mathrm{~N}$ L-IPSCs exhibited STD at a PPI of $300 \mathrm{~ms}$ (left) that recovered at a PPI of $1900 \mathrm{~ms}$ (right). OFF L-IPSCs exhibited weak STD at a PPI of $300 \mathrm{~ms}$ (left) and strong STD at a PPI of $1900 \mathrm{~ms}$ (right). Traces shown (red) are averages of five stimulations. C, The PPR for L-IPSC charge transfer is shown for ON L-IPSC in the presence of NBQX (left) and SR (middle) and for OFFL-IPSCs in the presence of SR (right). Data (mean \pm SE) at PPIs from 300 to 1900 ms were compared with a null PPR of one (statistical significance indicated by green asterisks), indicated by the horizontal dashed lines (black). PPRs $>1$ indicated STF, whereas values $<1$ indicated STD. In addition, data for control (black) and NBQX (blue) or SR (red) at each PPI were directly compared (purple brackets, asterisks). Number of cells in each condition ranged from 5 to $39 .{ }^{*} p<0.05,{ }^{* *} p<0.01,{ }^{* * *} p<0.001$.

L-IPSCs triggered by direct depolarization of ACs presynaptic to the Mb terminal display large latencies and asynchronous release

Consistent with the TTX sensitivity of glutamate puff-evoked lateral inhibition onto RBCs in the rat IPL (Chávez et al., 2010), our previous work showed that TTX attenuated OFF L-IPSCs and had mixed effects on ON L-IPSCs (Vigh et al., 2011). This suggested that two separate populations of ACs, only one of which expresses voltagegated $\mathrm{Na}^{+}$channels (OFF), might mediate ON and OFF L-IPSCs at the $\mathrm{Mb}$ terminal. Furthermore, differential effects of TTX $(0.2-5 \mu \mathrm{M}$ in the presence of $25 \mu \mathrm{M} \mathrm{SR}$ ) on the onset latencies of ON L-IPSCs (SRlatency, $68.3 \pm 3.4 \mathrm{~ms}, n=29$; TTX + SRlatency, $74.9 \pm 4.1 \mathrm{~ms}$, $n=23 ; p>0.05$, unpaired Student's $t$ test, two tailed) and OFF L-IPSCs (SR latency, $158.8 \pm 11.1 \mathrm{~ms}, n=22$; TTX + SR latency, $205.6 \pm 17.9 \mathrm{~ms}, n=10 ; p<0.05$ ) in the present study (data not shown) supported the idea that voltage-gated $\mathrm{Na}^{+}$channels selectively amplify and accelerate light responses in the ACs that mediate OFF L-IPSCs. Such a role for voltage-gated $\mathrm{Na}^{+}$channels in AClight responses has been demonstrated previously for inhibitory inputs to GCs mediated by AII ACs in mouse retina (Tian et al., 2010).
To discover the identity of the distinct AC classes involved in $\mathrm{ON}$ and $\mathrm{OFF}$ L-IPSCs, we performed paired recordings of intact $\mathrm{Mb}$ terminals and nearby $\mathrm{ACs}$ (Fig. $7 A, B$ ). In a small percentage of ACs, a somatic step depolarization from -70 to $0 \mathrm{mV}$ evoked L-IPSCs in the Mb terminal (only 3 of 39 pairs; connectivity, $\sim 7.7 \%$; Fig. $7 A, B)$. Of these three laterally connected ACs, none of which showed AC EPSCs after Mb depolarization (data not shown), two were diffuse or bistratified, and one (Fig. 7A) appeared to stratify primarily in the ON sublamina of the IPL. In the remaining 36 of 39 paired recordings, EPSCs were evoked in ACs after step depolarization of the $\mathrm{Mb}$ terminal from -70 to $0 \mathrm{mV}$, but stimulation in the reverse direction (from $\mathrm{AC} \rightarrow \mathrm{Mb}$ ) failed to evoke L-IPSCs. Although it is possible that ACs that exhibited unidirectional lateral synaptic connectivity in either direction (Mb $\rightarrow \mathrm{AC}$ or $\mathrm{AC} \rightarrow \mathrm{Mb}$ ) belong to separate functional classes, we were not able to discern clear morphological differences between these two groups based on reconstructions from confocal images. Because all ACs selected were within 50 $\mu \mathrm{m}$ of the soma of the recorded $\mathrm{Mb}$, it is possible that we failed to characterize certain classes of wide-field ACs that may make the majority of the lateral inhibitory synapses onto the Mb terminal.

The AC $\rightarrow$ Mb paired recordings revealed an unexpectedly slow L-IPSC onset latency of $106.1 \pm 76.0 \mathrm{~ms}(n=3$; Fig. $7 A, B)$. Such long latencies, which are much larger than the time course of a typical synaptic delay $(\sim 1 \mathrm{~ms})$, may have been attributable to incomplete voltage clamp of distal sections of AC dendritic arbors (Koizumi et al., 2005). This would produce slow depolarization and eventually activate voltage-gated $\mathrm{Na}^{+}$channels, triggering an escaping dendritic action potential (Koizumi et al., 2005) that would result in the relatively sharp, consistent IPSC onsets that we observed in the $\mathrm{Mb}$ terminal (Fig. 7B, IPSC latency). A similar delayed dendritic $\mathrm{Na}^{+}$action potential in OFF ACs, subsequent to spatiotemporal summation of small EPSCs arriving from multiple BC presynaptic terminals, could explain the long onset latencies that we observed for light-evoked OFF IPSCs, especially under mesopic background conditions (Figs. 4, 5). However, the rare occurrence and extreme technical difficulty of obtaining synaptically connected pairs of $\mathrm{AC} \rightarrow \mathrm{Mb}$ recordings prevented us from further testing this mechanism with bath or focal application of TTX.

Interestingly, Mb L-IPSCs in paired recordings also showed strong asynchronous release after a somatic repolarizing step to $-70 \mathrm{mV}$ in the recorded AC (Fig. $7 B$ ). Response duration in $\mathrm{Mb}$ terminals stimulated with a $200 \mathrm{~ms}$ depolarizing step in ACs was $383.9 \pm 95.8 \mathrm{~ms}(n=3)$. A possible mechanism for this asynchronous GABA release from ACs (183.9 $\pm 95.8 \mathrm{~ms}$ in duration), which could act to both truncate Mb glutamate release and im- 
pose a relative refractory period for lightevoked depolarization, is the accumulation of cytoplasmic $\mathrm{Ca}^{2+}$ subsequent to activation of voltage-dependent $\mathrm{Ca}^{2+}$ channels (Gleason et al., 1994). Such residual $\mathrm{Ca}^{2+}$ accumulation in the AC boutons that mediate OFF L-IPSCs would provide a possible mechanism for light-evoked OFF facilitation and latency advance (Figs. 3, 4).

\section{Discussion}

We have shown that the light-evoked, trisynaptic ON and OFF L-IPSCs at Mb BC terminals exhibit distinct temporal profiles of STP. ON L-IPSCs (Fig. 8, left, blue) exhibited amplitude depression (STD) of $\sim 45 \%$ at $50 \mathrm{~ms}$ that recovered to $\sim 10 \%$ at $1900 \mathrm{~ms}$, and onset latency delay of 95\% at $50 \mathrm{~ms}$ that fully recovered at $1900 \mathrm{~ms}$. OFF L-IPSCs (Fig. 8, right, red) displayed amplitude STD of $\sim 20 \%$ at $300 \mathrm{~ms}$, amplitude facilitation (STF) of $\sim 25 \%$ at 1900 ms, and latency advance of $\sim 15 \%$ at 300 $\mathrm{ms}$ that recovered at $1900 \mathrm{~ms}$. The recovery of ON and OFF STD ( $\tau \sim 500 \mathrm{~ms})$ was rapid compared with STD of Mb exocytosis ( $\tau \sim 8$ s; von Gersdorff and Matthews, $1997)$ and reciprocal inhibition $(\tau \sim 12 \mathrm{~s}$; Li et al., 2007) and therefore likely acts as a temporal high-pass filter of $\mathrm{Mb}$ glutamate release onto AC and GC dendrites (Sagdullaev et al., 2011). To clarify the functional roles of L-IPSC STP, we showed that changing background light from mesopic to scotopic increased the size and latency of ON L-IPSCs but increased the size and decreased the latency of OFF L-IPSCs. Next, we used pharmacology to identify $\mathrm{HC} \rightarrow$ photoreceptor feedback and $\mathrm{AC} \rightarrow \mathrm{AC}$ serial inhibitory circuits that shape ON and OFF STP, respectively (Fig. 8, middle). Finally, we showed that L-IPSCs evoked by depolarizing voltage steps at AC somata had long ( $\sim 100 \mathrm{~ms})$

latencies, consistent with the large delays of light-evoked OFF L-IPSCs, and exhibited sustained and asynchronous release $(\sim 200 \mathrm{~ms})$, consistent with the idea that $\mathrm{Ca}^{2+}$ accumulation in AC boutons may account for OFF facilitation and latency advance (Fig. 7). Together, these findings describe a novel scheme for STP of convergent, temporally independent lateral feedback inhibitory inputs at the $\mathrm{BC}$ presynaptic terminal.

Effects of L-IPSC plasticity on Mb terminal light responses likely depend on background light conditions

Under scotopic background, in which the $\mathrm{Mb}$ resting potential $\left(E_{\mathrm{m}}\right)$ has been measured at between -40 and $45 \mathrm{mV}$ (Protti et al., 2000; Baden et al., 2011), light responses at intact Mb terminals consist of either "analog" EPSPs with onset latencies of $\sim 50$ to $100 \mathrm{~ms}$ (Joselevitch and Kamermans, 2007) or "digital" $\mathrm{Ca}^{2+}$ action potentials with latencies of 75-90 ms (Protti et al., 2000; Baden et al., 2011). We expect, under these conditions, that ON L-IPSCs with latencies of 50-100 ms and a conductance of $1 \mathrm{nS}$
(Fig. 5) at a membrane potential of $-40 \mathrm{mV}$ could transiently hyperpolarize the $\mathrm{Mb}$ terminal by up to $10 \mathrm{mV}$, assuming an $E_{\mathrm{Cl}}$ of $-60 \mathrm{mV}$ and an input resistance of $\sim 500 \mathrm{M} \Omega$ (Protti et al., 2000 ), or reduce the EPSP peak by up to $70 \%$ (Oltedal et al., 2009). ON L-IPSC depression of $10-45 \%$ (Fig. 8, left), then, would be expected to decrease the size of subsequent IPSPs to between 5 and $9 \mathrm{mV}$ and to reduce attenuation of the EPSP peak to between 40 and $60 \%$. In addition, ON latency delay of $95 \%$ during high-frequency surround stimulation (Fig. 8, left) would eliminate block of the EPSP peak (Oltedal et al., 2009) but allow significant inhibition of the sustained component, which can last from $\sim 200$ to $500 \mathrm{~ms}$ (Joselevitch and Kamermans, 2007). We expect that OFF L-IPSCs, with latencies of $\sim 70 \mathrm{~ms}$ and amplitudes of $\sim 35 \mathrm{pA}$ (Fig. 5), would have effects similar to $\mathrm{ON}$ L-IPSCs under these conditions during naturalistic transient changes in surround luminance but would exert increased influence over the EPSP peak during repeated surround stimulation at intermediate and long PPIs as a result of $\sim 15 \%$ latency advance and $\sim 25 \%$ amplitude facilitation (Fig. 8, right). 


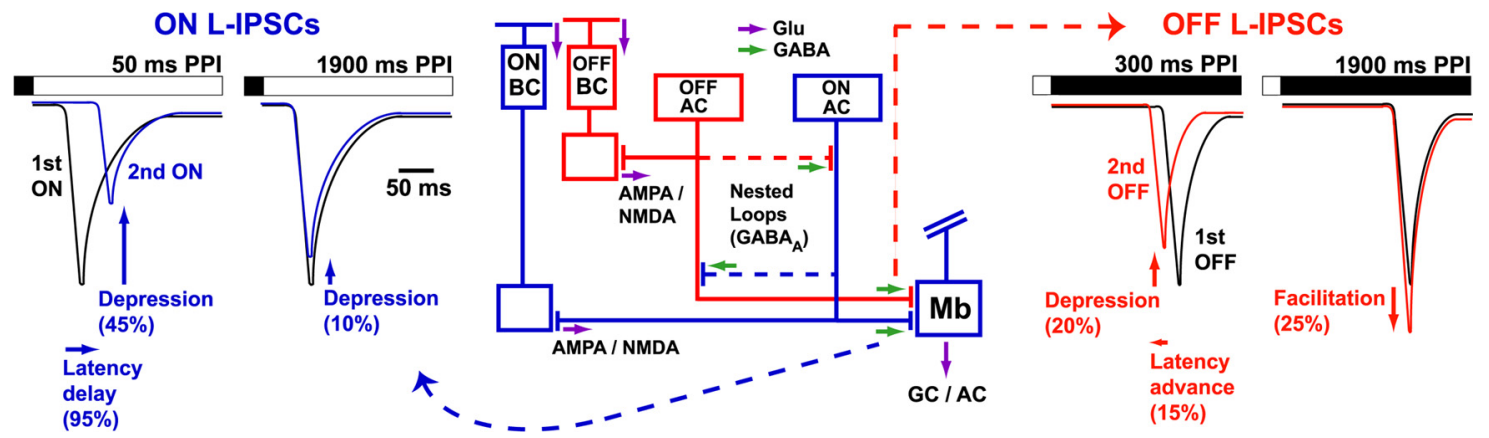

Figure 8. Schematic summary of the circuitry and receptors involved in STP in both size and latency of ON (left; blue) and OFF (right; red) GABAergic L-IPSCs recorded at axotomized Mb BC terminals. Note that, although BC to AC synaptic transmission in both the ON and OFF pathways is mediated by a combination of signaling at AMPA and NMDA receptors (middle diagram), ON L-IPSCS were potentiated (Vigh et al., 2011) and exhibited enhanced STD in the presence of NBQX (Fig. 6A). Similarly, although GABA $A_{A}$ signaling occurs at nested loop synapses (middle diagram; dashed lines) from ON $\rightarrow$ OFF and OFF $\rightarrow$ ON ACs, block of GABA $A_{A}$ Rs with SR reduced STD and STF of OFF L-IPSCS but had little or no effect on STP of ON L-IPSCS (Fig. 6B). Temporal profiles of paired light flash STP of both size (depression and facilitation) and latency (delay and advance), taken from population means (Figs. 3, 4), are illustrated by an overlay of peak normalized and shifted L-IPSCs at PPIs of 50 and $1900 \mathrm{~ms}$ (ON, left) and 300 and $1900 \mathrm{~ms}$ (OFF, right). Idealized first L-IPSCs are shown in black, and second L-IPSCs are shown in blue (ON) or red (OFF). Arrows and percentages reflect normalized amplitude PPRs (vertical arrows) and $\Delta$ onset latencies (horizontal arrows).

The above estimates of the effects of L-IPSC plasticity on Mb light responses are based on a model of the rat RBC (Oltedal et al., 2007, 2009). Although this model uses a slightly higher axial resistance in the axon, higher specific membrane resistance, and smaller total cell capacitance than the two compartment model of goldfish Mb BCs (Mennerick et al., 1997), these differences result in only 39\% shorter length constants and $25 \%$ faster time constants for the RBC compared with the Mb BC. Because the cutoff frequency of the RBC model is already quite high $(\sim 500 \mathrm{~Hz})$ relative to the overall speed of retinal processing, it is unlikely that these small differences would have a significant effect on our estimates over the paired-pulse frequency range that we examined $(\sim 0.5-20 \mathrm{~Hz})$. In addition, although the $\mathrm{Mb} \mathrm{BC}$ would be expected to display both slightly faster EPSP propagation from its soma to its axon terminal and slower EPSP and IPSP decay time constants than the rat RBC, the effective cutoff frequency for the output of either class of $\mathrm{BC}$ is likely rate limited not by passive cable properties but by the slow opening kinetics of L-type $\mathrm{Ca}^{2+}$ channels (Freeman et al., 2011).

Under scotopic background, the $\mathrm{Mb}$ terminal can generate $\mathrm{Ca}^{2+}$ spikes when $E_{\mathrm{m}}$ is more depolarized than $-48 \mathrm{mV}$ (Baden et al., 2011). Thus, hyperpolarization of $5-10 \mathrm{mV}$ provided by ON or OFF L-IPSCs might be sufficient to prevent spike initiation at the $\mathrm{Mb}$ terminal. In addition, shunting inhibition by L-IPSCs likely exerts significant control over $\mathrm{Ca}^{2+}$ spike initiation at the Mb terminal (Hull et al., 2006a). Therefore, depression of ON and OFF L-IPSCs may be permissive for digital signaling at the Mb terminal. Furthermore, latency delay of ON L-IPSCs at short PPIs may decrease their ability to prevent spikes by shifting the time of their arrival to after threshold crossing. However, under circumstances in which surround stimulation is dominated by low-frequency decreases in luminance (i.e., $1900 \mathrm{~ms}$ PPI), facilitation of OFF L-IPSCs may result in reduced probability of $\mathrm{Mb}$ terminal $\mathrm{Ca}^{2+}$ spikes.

The effects of L-IPSC STP on Mb EPSPs under mesopic background would be expected to differ from those described above for scotopic background for two reasons. First, the latencies of light-evoked EPSPs at the Mb terminal likely advance under mesopic conditions ( $\sim 35-50 \mathrm{~ms}$; Wong et al., 2005), thus decreasing the effect of ON L-IPSCs on the EPSP peak. This decreased inhibition will be exacerbated during high-frequency stimulation, when ON L-IPSCs are even further delayed (Fig. 8, left). Second, the arrival delay between ON and OFF L-IPSCs in response to rapid, naturalistic fluctuations in surround luminance will increase after the shift from scotopic to mesopic conditions, from near coincidence to $\sim 100 \mathrm{~ms}$ (Fig. $5 B$ ). Thus, we would expect ON and OFF L-IPSCs under these conditions to exert independent frequency-dependent effects (i.e., via the strength of STP), acting to truncate the transient and sustained components of the analog $\mathrm{Mb}$ light response, respectively. This would allow ON L-IPSCs to shape the Mb representation of temporal contrast and OFF L-IPSCs to shape its representation of mean luminance (Oesch and Diamond, 2011). Thus, although ON and OFF L-IPSCs might act in concert to exert gain control and gate spike initiation at the $\mathrm{Mb}$ terminal under scotopic background, they may perform separate computational roles under cone dominant conditions.

\section{ON and OFF L-IPSC STP are shaped by distinct mechanisms} Because block of $\mathrm{GABA}_{\mathrm{A}}$ Rs had little effect on ON L-IPSC depression (Fig. 6), it is unlikely that ON depression was attributable to $\mathrm{GABA}_{\mathrm{A}} \mathrm{R}$ desensitization or the influences of plasticity at upstream $\mathrm{GABA}_{\mathrm{A}}$ synapses. In addition, enhancement of $\mathrm{ON}$ depression at the $300 \mathrm{~ms}$ PPI (Fig. 6) after block of AMPARs with NBQX (Fig. 8, middle) suggested that surround feedback inhibition from HCs to photoreceptors (Fahrenfort et al., 2005, 2009) may significantly compress the dynamic range of ON BC light responses and thereby minimize vesicle depletion at $\mathrm{ON} B C$ and ON AC synapses. Thus, minimization of HC membrane potential fluctuations via block of AMPARs on HC dendrites would allow $\mathrm{ON} \mathrm{BCs}$ to be more hyperpolarized in the dark and to experience greater depolarization during light stimulation of photoreceptors. This might both accelerate recovery of the readily releasable pool of glutamatergic vesicles at the $\mathrm{Mb}$ terminal in the dark and enhance depression attributable to increased vesicle depletion during the light stimulus (Jarsky et al., 2011). Therefore, it seems likely that ON depression and latency delay under control conditions are driven by a combination of vesicle depletion at neighboring BC terminals (von Gersdorff and Matthews, 1997) and presynaptic ACs (Li et al., 2007) and that these mechanisms are enhanced by removal of feedback inhibition in the outer retina.

STP of OFF L-IPSCs was regulated by mechanisms distinct from those involved in ON STP. OFF depression at short PPIs was diminished or absent after blockade of $\mathrm{GABA}_{\mathrm{A}} \mathrm{Rs}$ (Fig. 6). This result suggested that $\mathrm{GABA}_{\mathrm{A}} \mathrm{R}$ desensitization at the $\mathrm{Mb}$ 
terminal might contribute to OFF depression. This is consistent with the previous finding that $\mathrm{Mb} \mathrm{GABA}_{\mathrm{A}} \mathrm{Rs}$ can recover fully from desensitization within 1-2 s (Li et al., 2007). OFF amplitude facilitation at long PPIs (Fig. 8, right), which was attenuated by SR block of $\mathrm{GABA}_{\mathrm{A}}$ Rs at $\mathrm{AC} \rightarrow \mathrm{AC}$ synapses, may be attributable to progressive disinhibition via serial AC pathways (i.e., depression within nested loops; see Fig. 8, middle). In addition, the sustained and asynchronous L-IPSCs evoked in our paired recordings (Fig. 7), along with the latency advances displayed by paired OFF L-IPSCs (Fig. 8, right), are both consistent with the idea that OFF facilitation may be driven, in part, by intracellular residual $\mathrm{Ca}^{2+}$ accumulation and increased release probability at OFF AC presynaptic boutons (Gleason et al., 1994).

\section{Potential physiological roles of L-IPSC STP at BC terminals}

Filtering of transient or sustained glutamate release by STP of ON and OFF L-IPSCs at the Mb terminal may enable postsynaptic GCs (and ACs) to rapidly modify the strength and extent of their inhibitory surrounds after changes in surround temporal contrast. Such dynamic spatial coupling may play a role in the rapid coding of spatial information as relative GC spike onset latencies $( \pm 30 \mathrm{~ms})$ after saccadic gaze relocation, wherein local spatial contrast determines the ratio between convergent OFF (early) and ON (late) BC inputs onto individual GC dendrites (Gollisch and Meister, 2008). STP in the size and timing of ON (early) and OFF (late) L-IPSCs driven by distal BC inputs would introduce frequency-dependent correlations between spike latencies across a population of GCs, thus enabling the extraction of spatial information by downstream decoders (Usrey et al., 2000; Chase and Young, 2007).

\section{References}

Arai I, Tanaka M, Tachibana M (2010) Active roles of electrically coupled bipolar cell network in the adult retina. J Neurosci 30:9260-9270.

Baden T, Esposti F, Nikolaev A, Lagnado L (2011) Spikes in retinal bipolar cells phase-lock to visual stimuli with millisecond precision. Curr Biol 21:1859-1869.

Billups D, Attwell D (2002) Control of intracellular chloride concentration and GABA response polarity in rat retinal ON bipolar cells. J Physiol 545:183-198.

Busskamp V, Duebel J, Balya D, Fradot M, Viney TJ, Siegert S, Groner AC, Cabuy E, Forster V, Seeliger M, Biel M, Humphries P, Paques M, Mohand-Said S, Trono D, Deisseroth K, Sahel JA, Picaud S, Roska B (2010) Genetic reactivation of cone photoreceptors restores visual responses in retinitis pigmentosa. Science 329:413-417.

Chase SM, Young ED (2007) First-spike latency information in single neurons increases when referenced to population onset. Proc Natl Acad Sci USA 104:5175-5180.

Chávez AE, Grimes WN, Diamond JS (2010) Mechanisms underlying lateral GABAergic feedback onto rod bipolar cells in rat retina. J Neurosci 30:2330-2339.

Cook PB, McReynolds JS (1998) Lateral inhibition in the inner retina is important for spatial tuning of ganglion cells. Nat Neurosci 1:714-719.

Dowling JE, Werblin FS (1969) Organization of retina of the mudpuppy, Necturus maculosus. I. Synaptic structure. J Neurophysiol 32:315-338.

Duebel J, Haverkamp S, Schleich W, Feng G, Augustine GJ, Kuner T, Euler T (2006) Two-photon imaging reveals somatodendritic chloride gradient in retinal ON-type bipolar cells expressing the biosensor Clomeleon. Neuron 49:81-94.

Eggers ED, Lukasiewicz PD (2010) Interneuron circuits tune inhibition in retinal bipolar cells. J Neurophysiol 103:25-37.

Euler T, Masland RH (2000) Light-evoked responses of bipolar cells in a mammalian retina. J Neurophysiol 83:1817-1829.

Fahrenfort I, Klooster J, Sjoerdsma T, Kamermans M (2005) The involvement of glutamate-gated channels in negative feedback from horizontal cells to cones. Prog Brain Res 147:219-229.

Fahrenfort I, Steijaert M, Sjoerdsma T, Vickers E, Ripps H, van Asselt J, Endeman D, Klooster J, Numan R, ten Eikelder H, von Gersdorff H,
Kamermans M (2009) Hemichannel-mediated and pH-based feedback from horizontal cells to cones in the vertebrate retina. PLoS One 4:e6090.

Freeman DK, Jeng JS, Kelly SK, Hartveit E, Fried SI (2011) Calcium channel dynamics limit synaptic release in response to prosthetic stimulation with sinusoidal waveforms. J Neural Eng 8:046005.

Gillis KD (2000) Admittance-based measurement of membrane capacitance using the EPC-9 patch-clamp amplifier. Pflugers Arch 439:655-664

Gleason E, Borges S, Wilson M (1994) Control of transmitter release from retinal amacrine cells by $\mathrm{Ca}^{2+}$ influx and efflux. Neuron 13:1109-1117.

Gollisch T, Meister M (2008) Rapid neural coding in the retina with relative spike latencies. Science 319:1108-1111.

Hsueh HA, Molnar A, Werblin FS (2008) Amacrine-to-amacrine cell inhibition in the rabbit retina. J Neurophysiol 100:2077-2088.

Hull C, Li GL, von Gersdorff H (2006a) GABA transporters regulate a standing $\mathrm{GABA}_{\mathrm{C}}$ receptor-mediated current at a retinal presynaptic terminal. J Neurosci 26:6979-6984.

Hull C, Studholme K, Yazulla S, von Gersdorff H (2006b) Diurnal changes in exocytosis and the number of synaptic ribbons at active zones of an ON-type bipolar cell terminal. J Neurophysiol 96:2025-2033.

Ichinose T, Lukasiewicz PD (2005) Inner and outer retinal pathways both contribute to surround inhibition of salamander ganglion cells. J Physiol 565:517-535.

Ichinose T, Lukasiewicz PD (2007) Ambient light regulates sodium channel activity to dynamically control retinal signaling. J Neurosci 27:4756-64.

Ichinose T, Shields CR, Lukasiewicz PD (2005) Sodium channels in transient retinal bipolar cells enhance visual responses in ganglion cells. J Neurosci 25:1856-1865.

Jacobs AL, Werblin FS (1998) Spatiotemporal patterns at the retinal output. J Neurophysiol 80:447-451.

Jarsky T, Cembrowski M, Logan SM, Kath WL, Riecke H, Demb JB, Singer JH (2011) A synaptic mechanism for retinal adaptation to luminance and contrast. J Neurosci 31:11003-11015.

Joselevitch C, Kamermans M (2007) Interaction between rod and cone inputs in mixed-input bipolar cells in goldfish retina. J Neurosci Res 85:1579-1591.

Joselevitch C, Kamermans M (2009) Retinal parallel pathways: seeing with our inner fish. Vision Res 49:943-959.

Kastner DB, Baccus SA (2011) Coordinated dynamic encoding in the retina using opposing forms of plasticity. Nat Neurosci 14:1317-1322.

Kim MH, Vickers E, von Gersdorff H (2012) Patch-clamp capacitance measurements and $\mathrm{Ca}^{2+}$ imaging at single nerve terminals in retinal slices. J Vis Exp 19:pii:3345.

Koizumi A, Hayashida Y, Kiuchi T, Yamada Y, Fujii A, Yagi T, Kaneko A (2005) The interdependence and independence of amacrine cell dendrites: patch clamp recordings and simulation studies on cultured GABAergic amacrine cells. J Integr Neurosci 4:363-380.

Koulen P, Brandstätter JH, Enz R, Bormann J, Wässle H (1998) Synaptic clustering of $\mathrm{GABA}(\mathrm{C})$ receptor rho-subunits in the rat retina. Eur J Neurosci 10:115-127.

Krizaj D (2000) Mesopic state: cellular mechanisms involved in pre- and post-synaptic mixing of rod and cone signals. Microsc Res Tech 50:347-359.

Li GL, Vigh J, von Gersdorff H (2007) Short-term depression at the reciprocal synapses between a retinal bipolar cell terminal and amacrine cells. J Neurosci 27:7377-7385.

Lukasiewicz PD, Eggers ED, Sagdullaev BT, McCall MA (2004) GABA receptor-mediated inhibition in the retina. Vision Res 44:3289-3296.

Manu M, Baccus SA (2011) Disinhibitory gating of retinal output by transmission from an amacrine cell. Proc Natl Acad Sci USA 108:18447-18452.

Marc RE, Liu W (2000) Fundamental GABAergic amacrine cell circuitries in the retina: nested feedback, concatenated inhibition, and axosomatic synapses. J Comp Neurol 425:560-582.

Matthews G, Ayoub GS, Heidelberger R (1994) Presynaptic inhibition by GABA is mediated via two distinct GABA receptors with novel pharmacology. J Neurosci 14:1079-1090.

Mennerick S, Zenisek D, Matthews G (1997) Static and dynamic membrane properties of large-terminal bipolar cells from goldfish retina: experimental test of a compartmental model. J Neurophysiol 78:51-62.

Oesch NW, Diamond JS (2011) Ribbon synapses compute temporal contrast and encode luminance in retinal rod bipolar cells. Nat Neurosci 14:1555-1561. 
Oltedal L, Mørkve SH, Veruki ML, Hartveit E (2007) Patch-clamp investigations and compartmental modeling of rod bipolar axon terminals in an in vitro thin-slice preparation of the mammalian retina. J Neurophysiol 97:1171-1187.

Oltedal L, Veruki ML, Hartveit E (2009) Passive membrane properties and electrotonic signal processing in retinal rod bipolar cells. J Physiol $587: 829-849$.

Palmer MJ (2006) Functional segregation of synaptic $\mathrm{GABA}_{\mathrm{A}}$ and $\mathrm{GABA}_{\mathrm{C}}$ receptors in goldfish bipolar cell terminals. J Physiol 577:45-53.

Palmer MJ, Hull C, Vigh J, von Gersdorff H (2003) Synaptic cleft acidification and modulation of short-term depression by exocytosed protons in retinal bipolar cells. J Neurosci 23:11332-11341.

Protti DA, Flores-Herr N, von Gersdorff H (2000) Light evokes $\mathrm{Ca}^{2+}$ spikes in the axon terminal of a retinal bipolar cell. Neuron 25:215-227.

Sagdullaev BT, Eggers ED, Purgert R, Lukasiewicz PD (2011) Nonlinear interactions between excitatory and inhibitory retinal synapses control visual output. J Neurosci 31:15102-15112.

Snellman J, Zenisek D, Nawy S (2009) Switching between transient and sustained signaling at the rod bipolar-AII amacrine cell synapse of the mouse retina. J Physiol 587:2443-2455.

Tian M, Jarsky T, Murphy GJ, Rieke F, Singer JH (2010) Voltage-gated Na channels in AII amacrine cells accelerate scotopic light responses mediated by the rod bipolar cell pathway. J Neurosci 30:4650-4659.

Usrey WM, Alonso JM, Reid RC (2000) Synaptic interactions between thalamic inputs to simple cells in cat visual cortex. J Neurosci 20:5461-5467.

Venkataramani S, Taylor WR (2010) Orientation selectivity in rabbit retinal ganglion cells is mediated by presynaptic inhibition. J Neurosci 30:15664-15676.

Vigh J, von Gersdorff H (2005) Prolonged reciprocal signaling via
NMDA and GABA receptors at a retinal ribbon synapse. J Neurosci 25:11412-11423.

Vigh J, Vickers E, von Gersdorff H (2011) Light-evoked lateral GABAergic inhibition at single bipolar cell synaptic terminals is driven by distinct retinal microcircuits. J Neurosci 31:15884-15893.

von Gersdorff H, Matthews G (1997) Depletion and replenishment of vesicle pools at a ribbon-type synaptic terminal. J Neurosci 17:1919-1927.

von Gersdorff H, Matthews G (1999) Electrophysiology of synaptic vesicle cycling. Annu Rev Physiol 61:725-752.

Wang P, Slaughter MM (2005) Effects of GABA receptor antagonists on retinal glycine receptors and on homomeric glycine receptor alpha subunits. J Neurophysiol 93:3120-3126.

Watanabe S, Koizumi A, Matsunaga S, Stocker JW, Kaneko A (2000) GABA-mediated inhibition between amacrine cells in the goldfish retina. J Neurophysiol 84:1826-1834.

Witkovsky P, Dowling JE (1969) Synaptic relationships in the plexiform layers of carp retina. Z Zellforsch Mikrosk Anat 100:60-82.

Wong KY, Cohen ED, Dowling JE (2005) Retinal bipolar cell input mechanisms in giant danio. II. Patch-clamp analysis of on bipolar cells. J Neurophysiol 93:94-107.

Zenisek D, Matthews G (1998) Calcium action potentials in retinal bipolar neurons. Vis Neurosci 15:69-75.

Zenisek D, Henry D, Studholme K, Yazulla S, Matthews G (2001) Voltagedependent sodium channels are expressed in nonspiking retinal bipolar neurons. J Neurosci 21:4543-4550.

Zhang AJ, Wu SM (2009) Receptive fields of retinal bipolar cells are mediated by heterogeneous synaptic circuitry. J Neurosci 29:789-797.

Zhang J, Jung CS, Slaughter MM (1997) Serial inhibitory synapses in the retina. Vis Neurosci 14:553-563. 